subjects it passes entirely to the right side before it turns back to the mid-line of the sacrum and becomes rectum. I can give no reason for the curved part of this bowel or for the variation and extent of its curvature, unless it be that by holding up the more solid fæces, it so prevents the undue desire for their propulsion until an opportune moment; but this $I$ repeat is mere speculation. The rectum itself is a purely pelvic organ. It is only partially invested by peritoneum, but a knowledge of this investiture is important. The first portion is entirely covered by peritoneum; the second portion is only partially covered by peritoneum, whilst the third portion is entirely denuded of this coat. Now if you recollect that the third portion of the rectum is an inch long, that the second portion of it is only about three or four inches, and as I have said only the upper part covered by peritoneum, it follows that operations on the lower part of the gut must be conducted with care if you wish to avoid entering the serous cavity. Roughly speaking, in any surgical interference with the rectum three inches from the anus is about the limit of the field in which there is no danger of entering the peritoneal cavity.

In conclusion, it will be obvious to you all that I can only give you a cursory description of the principal relations of the important organs and structures in the thorax and abdomen, but if in the short time that has been at our disposal I shall have refreshed your memory of the anatomy of these organs, and if I shall have also given you any aid to diagnosis and treatment, my object will have been accomplished.

\section{TYPHOID FEVER.}

Is opening a discussion at Cheltenham on enteric fever Dr. Houston commenced by saying that he was greatly struck with the fact that notwithstanding the progress of science and the great efficiency of the public health service, we find ourselves at the beginning of a new century unable to stamp out a disease which is, nevertheless, still classed as a preventable one; and after careful review of the present position of our knowledge in regard to the natural history, the modes of dissemination, and the prcphylaxis of the disease, he ended by the remark that the discoveries of recent times have but confirmed the wisdom of the teaching of epidemiologists at a time when the science of bacteriology was unknown or only in its infancy. In illustration of this he quoted from the late Sir Richard Thorne Thorne's introduction to the Local Government Board report on Oyster Culture in Relation to Disease as follows:- "Long before Koch's cholera vibrio or Eberth's typhoid bacillus had been even heard of, the remarkable progress made in the prevention of cholera and of enteric fever in this country was the result of the recognition of the fact that water and food, amongst other things, which had been subject to contamination by human excreta, served as channels for the communication of the specific contagia of those diseases to man." The general measures which have governed sanitarians in the past remain the same to-day. These are (1) to protect our water supplies from excremental pollution; (2) to secure that all articles of food are free from objectionable contamination; (3) to secure that our drains and sewers are kept in good order; and (4) to disinfect the stools and urine and soiled linen of enteric fever patients. In regard to the latter point he urged the administration of urotropine throughout the whole course of the disea:e and for some weeks afterwards in all cases of enteric fever. When it is remembered that every fourth case may present this serious complication, that every drop of such urine may contain not only thousands but millions of typhoid bacilli, and that soiling of the linen with urine is impossible to avoid, the extreme importance of the subject will be readily admitted. In nearly all cases, he says, urotropine may be given in 30-grain doses for months without any ill effects, and without prejudice to other medicines and the usual treatment of the disease. It is true, he adds, that in a few cases hæmaturia and albuminuria have been caused by its use, but on ceasing the administration of the drug these symptoms have rapidly disappeared. On public health grounds then he urged in the strongest manner " that this valuable remedy should be administered in all cases of enteric fever." As to the utility of anti-typhoid inoculations he was by no means so positive. In India, the results have been of an encouraging nature, but as regards South Africa, while some competent authorities have spoken very favourably of the results, others equally competent have arrived at an opposite conclusion. However the results are interpreted it cannot, he says, be expected that preventive inoculation has any great future before it in this country. It is chiefly in the case of people going abroad and as regards our troops serving in India, South Africa, and other places where typhoid fever is very prevalent, that such inoculations would be most serviceable, if it should be shown that they can do what is claimed for them.

\section{THE ETHICS OF USING UROTROPINE.}

THE above suggestion that, with the object of destroying the typhoid bacilli so often present in the urine of patients suffering from enteric fever, all such patients should undergo a course of urotropine, raises certain ethical questions. The observation that urotropine occasionally produces hæmaturia, has led Dr. Handford, of Nottingham, to say that however advantageous it may be from a public health point of view to kill off the bacilli in this way, the question arises whether it is justifiable to administer a drug to a patient with any other object than his own cure, especially when it has been shown that the drug in question may, and does occasionally, do harm. We agree with him in his protest against the routine use of this drug for any such purpose as disinfecting the urine for the public good. Any drug which might give rise to hæmaturia ought only to be given when of benefit to the patient. We must find other means for rendering the urine innocuous as we have perforce to do in the case of the other excreta.

\section{WATER TYPHOID.}

Speaking at Cheltenham, Dr. Reynolds, Commissioner of Health, Chicago, said that Chicago was supplied with water from Lake Michigan by four tunnels under the lake ranging in length from two to four miles. Each day a sample of water collected from the shore end of each tunnel was carefully analysed both chemically and bacteriologically, and it was found that when any pollution of the water was discovered this was followed by a rise in the mortality from typhoid fever and from acute intestinal diseases, the rise taking place in the case of typhoid fever in about five weeks and in the case of the other diseases in about one week. This seems to be a matter of considerable importance in view of the statement so often made, a statement which has received the endorse- 